\title{
CAMBIO CLIMÁTICO Y POPULISMOS EN AMÉRICA LATINA: UN ANÁLISIS COMPARATIVO DE LOS POSICIONAMIENTOS DE ARGENTINA, ECUADOR, CHILE Y BRASIL EN EL CAMINO AL ACUERDO DE PARÍS DE 2015
}

\author{
CLIMATE CHANGE AND POPULISMS IN LATIN AMERICA: \\ A COMPARATIVE ANALYSIS OF THE POSITIONS OF ARGENTINA, ECUADOR, CHILE \\ AND BRAZIL IN VIEW OF THE 2015 PARIS AGREEMENT
}

Jorge Foa Torres

(Consejo Nacional de Investigaciones Científicas y Técnicas / Argentina) jorgefoatorres@gmail.com

Recibido: 11/09/2018

Aprobado: 30/10/2018

\begin{abstract}
RESUMEN
Frente a diversas críticas a lo populista que suelen pronunciarse desde el campo ambiental, este trabajo presenta un análisis comparativo de los posicionamientos Argentina, Ecuador, Chile y Brasil en las recientes negociaciones internacionales desde la Conferencia de las Partes de Copenhague hasta el Acuerdo de París de 2015.

El artículo se ordena en función de las siguientes preguntas de investigación: ¿de qué manera las prácticas discursivas enunciadas en los foros internacionales relativos a cambio climático por Argentina, Ecuador, Chile y Brasil significan a los problemas ambientales globales, sus posibles soluciones y al rol de los Estados Latinoamericanos en tales procesos? ¿Cuáles diferencias y similitudes entre los posicionamientos discursivos de esos Estados es posible identificar? ¿De qué manera tales posicionamientos y coaliciones se vinculan a los procesos populistas latinoamericanos recientes?

La conclusión principal es que los procesos populistas tienden a tomar posicionamientos más radicalizados o antagónicos en cuanto al reclamo a los países desarrollados por la asunción de sus responsabilidades históricas en la generación del calentamiento global. Mientras los procesos no populistas tienden a hacer mayor énfasis en posturas pragmáticas facilitadoras del logro de acuerdos internacionales.
\end{abstract}

Palabras clave: Teoría política del discurso. Política ambiental. Responsabilidades comunes pero diferenciadas. Financiamiento climático.

\section{ABSTRACT}

In front of different critiques to the populist that usually pronounced from the environmental field, this paper presents a comparative analysis of the positions of Argentina, Ecuador, Chile and Brazil in the recent international negotiations regarding the Paris Agreement of 2015.

The work is based on the following research questions: how do the discursive practices enunciated in the international forums related to climate change by Argentina, Ecuador, Chile and Brazil mean global environmental problems, their possible solutions and the role of the Latin American States in such processes? What differences and similarities between the discursive positions of these States is it possible to identify? How do such positions and coalitions link to recent Latin American populist processes? 
The main conclusion is that populist processes tend to take more radicalized or antagonistic positions on the claim to developed countries for the assumption of their historical responsibilities in the generation of global warming. While non-populist processes tend to place more emphasis on pragmatic positions that facilitate the achievement of international agreements.

Keywords: Political Discourse theory. Environmental politics. Common but differentiated responsibilities. Climate financing.

\title{
Introducción
}

Diferentes críticas a lo populista han sido enunciadas desde el campo ambiental en los últimos tiempos. Veamos, en 1995 en pleno auge de la década neoliberal en América Latina, la por entonces economista superior del Banco Mundial Piritta Sorsa afirmaba que:

\begin{abstract}
En buena parte del debate político populista de hoy en día, el comercio (o mejor dicho, el libre comercio) se ha convertido en la causa de muchas deficiencias observadas o de los problemas económicos, trátese del aumento del desempleo o el deterioro del ambiente. El debate suscitado en EEUU en torno a los tratados de libre comercio muestra cuán lejos pueden llegar los argumentos populistas en contra del comercio (1995:101).
\end{abstract}

Mucho más cerca en el tiempo en una reciente publicación de la Fundación Verde Europea (GEF) de 2011 se afirmaba que

...el populismo plantea para un gran desafío para los partidos verdes en toda Europa en cuanto a revisar sus propias narrativas y conceptos políticos (...) Si ellos tienen la intención de ser importantes para el futuro de Europa, tendrán que ofrecer una alternativa real al populismo (Meijers, 2011: 12).

Desde América Latina, recientemente Maristella Svampa ha denunciado cierta articulación entre los populismos "de alta intensidad" en la región y el "paradigma extractivista". Aquellos basados en "una política confrontativa que engloba, en su lectura conspirativa, a las organizaciones ambientalistas y a sectores indígenas que hoy luchan contra el avance del extractivismo", se caracterizan por haber renunciado a la "dimensión emancipatoria de la política y la evolución hacia modelos de dominación de corte tradicional" (Svampa, 2016: 80/84).

Mientras otros orientan sus cuestionamientos a las experiencias latinoamericanas de izquierda y su "atracción populista por capitalizar los beneficios inmediatos de la explotación de los recursos naturales durante los ciclos electorales" (Edwards \& Timmons Roberts, 2015: 171).

Pero en este marco ¿a qué experiencias o posicionamientos políticos se hace referencia al nombrarlos como populistas? ¿Es lo populista una herramienta para identificar a las posturas proteccionistas o contrarias a los tratados libre comercio como señala Sorsa? ¿O acaso el populismo es esencialmente una amenaza para la causa ambiental y, por ende, para la lucha contra el cambio climático?

Es ya harto conocido y debatido el problema de la polisemia del término populista y la dificultad que reside en la ciencia política para precisar su definición ${ }^{1}$. No obstante, el objetivo de este trabajo no pasa por intervenir en tales discusiones, sino en dar cuenta de los posicionamientos efectivamente adoptados por las experiencias políticas populistas latinoamericanas. Especialmente en su diferenciación con los asumidos por países no populistas a los fines de echar luz a las relaciones entre la cuestión populista y la política ambiental.

La perspectiva para el análisis es la de la teoría política del discurso ${ }^{2}$ que articula elementos del posmarxismo y posfundacionalismo con el objetivo de comprender críticamente las prácticas socio-

\footnotetext{
${ }^{1}$ Entre otros: Laclau, 2008; Panizza, 2005; Stavrakakis, 2015; Rovira Kaltwasser, 2014a.

${ }^{2}$ Entre otros: Laclau \& Mouffe, 2004; Glynos \& Howarth, 2007.
} 
discursivas. Específicamente, este enfoque permite hacer énfasis en el carácter constitutivamente dividido de la realidad socialmente construida, es decir en la imposibilidad del acceso a un orden social pleno o a una sociedad finalmente reconciliada consigo misma (Laclau, 2000; Glynos \& Howarth, 2007). A partir de ello, especial interés se pone desde esta epistemología en el antagonismo social, en tanto síntoma o signo de esa imposible sutura o superación definitiva de la división social y los diferentes modos en que se manifiesta.

De tal manera, esta perspectiva no parte del supuesto de la existencia actual o futura de un consenso social, régimen, arquitectura u orden sobre el cual devienen determinados conflictos o desacuerdos y respecto del cual el cientista social debiera efectuar su labor de descripción y explicación. Por el contrario, todo régimen o arquitectura internacional se construye, desde la mirada posmarxista, sobre ciertos antagonismos estableciendo determinadas maneras de tratarlos, invisibilizarlos, reprimirlos o negarlos.

Por lo tanto, no se busca dar cuenta del nivel de efectividad de los regímenes internacionales sobre cambio climático sino comprender e identificar las diferentes lógicas políticas en pugna que los estructuran. Evitando caer en miradas prescriptivas que buscan (incluso en el caso del cambio climático) la superación final del antagonismo Norte-Sur en el terreno de las relaciones internacionales.

En este marco, la tesis de este trabajo es que los populismos latinoamericanos tienden, antes que a adoptar posturas poco ambiciosas o incluso negacionistas del cambio climático, a proponer soluciones vinculadas con la transformación más o menos radical del sistema económico-político internacional. Tales propuestas difieren profundamente de las derechas gobernantes y/o de las experiencias no populistas de la región que privilegian el arribo a consensos para el abordaje de la mitigación y adaptación al cambio climático, relegando la consideración de la historia de las emisiones de carbono y su vinculación con las relaciones de poder Norte-Sur.

\section{Los posicionamientos de Ecuador, Argentina, Chile y Brasil}

En este trabajo nos centraremos en las posturas de cuatro países latinoamericanos: Ecuador, Argentina, Brasil y Chile. Las fuentes documentales analizadas remiten, principalmente, a los discursos de mandatarios y representantes de cada país.

La selección de estos cuatro casos nos permite abordar el posicionamiento de las dos mayores economías de América del Sur, por un lado, y de dos países que integran activamente dos organismos regionales de gran relevancia en las negociaciones sobre cambio climático como la Alianza del Pacífico (Chile) y el ALBA (Ecuador). Pero fundamentalmente, nos posibilita comparar las diferentes miradas de las experiencias populistas, encarnadas en los casos de Ecuador y Argentina ${ }^{3}$, y no populistas, en Brasil y Chile.

Tanto los gobiernos de Néstor Kirchner y Cristina Fernández en Argentina como el de Rafael Correa en Ecuador suelen ser caracterizados por la literatura politológica como populistas. Ya sea que tales estudios asuman definiciones operativas del populismo ${ }^{4}$ o miradas que ven en la división maniquea de

\footnotetext{
${ }^{3}$ No obstante, cabe aclarar que, en el caso de Argentina, se produjo la sucesión presidencial durante la realización de la COP 21 cuestión que produjo cierto desplazamiento en la posición de nuestro país, aspecto que abordaremos más adelante.

${ }^{4}$ En base a la teoría de la hegemonía de Ernesto Laclau, la teoría política del discurso ha desarrollado un importante volumen de estudios teóricos y empíricos acerca de la cuestión populista: Laclau, 2006, 2008; Stavrakakis, 2015; entre otros. Una definición "operativa" o formal de populismo suele identificar una serie de elementos propios de la forma populista, tales como: la interpelación y articulación en torno al "pueblo" como punto nodal; una representación predominantemente antagonista de lo social, dicotomizando a la sociedad en dos grandes bloques; la articulación equivalencial de demandas populares insatisfechas; la emergencia y centralidad de la figura del líder en el lugar del ideal.
} 
la sociedad a su característica invariante ${ }^{5}$. Por otro lado, los procesos políticos recientes en Brasil y Chile, en relación con los gobiernos de Michelle Bachelet, Dilma Roussef y Luiz Inácio "Lula" da Silva, tienden a ser identificados como "izquierdas moderadas" (Rovira Kaltwasser, 2014b) o en una "posición intermedia" entre populismo e institucionalismo (Laclau, 2006).

El análisis comparativo se basa en la construcción de ejes de problematización que permiten identificar regularidades y variaciones de sentido tanto en cada uno de los casos como entre los casos estudiados. Es decir, posibilitan la caracterización del posicionamiento de cada país a través de la identificación de los puntos nodales que ciñen la significación de sus posturas en relación diferencial con otras identidades político-ideológicas en las negociaciones en cuestión. En orden a profundizar el problema de investigación, es decir, distinguir las prácticas discursivas de las experiencias populistas latinoamericanas recientes respecto de las derechas o experiencias no usualmente calificadas por la literatura politológica y de relaciones internacionales como "populistas".

Los ejes de problematización utilizados fueron:

a) Las coaliciones y grupos de negociación más relevantes política e ideológicamente de los que formaron parte: si bien los países de la región casi en su totalidad integran el Grupo de países en desarrollo más grande de Naciones Unidas denominado G 77 + China (México abandonó el grupo en el año 1994 para integrarse a la Organización y el Cooperación para el Desarrollo Económico: OCDE), también forman parte de subgrupos relevantes en las negociaciones como la Asociación Independiente de América Latina y el Caribe (AILAC), el Grupo de Países en Desarrollo con Posiciones Afines (LMDC, por sus siglas en inglés: Like Minded Group of Developing Countries), el Grupo BASIC (Brasil, Sudáfrica, India y China) y la reciente Coalición de Gran Ambición creada en París en 2015.

b) Los organismos de integración regional o extrarregional que integran: que poseen relevancia en cuanto a las concepciones político-ideológicas a las que adhieren en determinados momentos. Mientras los países de la AILAC están más vinculados a la Alianza del Pacífico, ciertos países latinoamericanos del LMDC se relacionan a la Alianza Bolivariana para los Pueblos de Nuestra América (ALBA).

c) Naturaleza del problema del cambio climático: si énfasis en las posturas está puesto en el carácter político-económico del problema, en su entidad técnico-científica o en su carácter moral.

d) Postura frente al Principio de Responsabilidades Comunes pero Diferenciadas ${ }^{6}$ : consagrado en $^{2}$ la Convención Marco de Naciones Unidas sobre Cambio Climático de $1992^{7}$ abrió el camino a diferentes interpretaciones. Los polos de esas interpretaciones varían entre posiciones fuertes vinculadas a las responsabilidades históricas en las emisiones de carbono y las pragmáticas que priorizan el consenso a cualquier costo.

e) Financiamiento y tecnologías para enfrentar al cambio climático: especialmente el modo en que los países más industrializados, y entre ellos con mayores responsabilidades históricas, debieran contribuir a financiar las medidas de mitigación y adaptación en los países menos desarrollados. Como así también, la transferencia tecnológica necesaria para el logro de una progresiva descarbonización de las economías del mundo.

f) Adaptación versus mitigación: es relevante advertir el énfasis que cada país pone ya sea a la mitigación o a la adaptación al cambio climático. Asimismo, el carácter o no voluntario de las medidas de mitigación para los países en desarrollo es un punto de interés en este eje de problematización, así como también las implicancias en términos de relaciones comerciales que el régimen internacional de lucha contra el calentamiento global puede conllevar.

\footnotetext{
${ }^{5}$ Desde este enfoque se "define al populismo como un particular discurso o ideología, el cual está basado en una distinción maniquea entre el pueblo puro y la elite corrupta, por la cual la primera es vista como una entidad virtuosa y la segunda como la fuente de todo lo malo" (Rovira Kaltwasser, 2014a: 496). Entre otros: De la Torre, 2014; Mudde \& Rovira, 2012. ${ }^{6}$ En adelante PRCPD.

7 "Las Partes deberían proteger el sistema climático (...) sobre la base de la equidad y de conformidad con sus responsabilidades comunes pero diferenciadas y sus respectivas capacidades" (NU, 1992: art. 3).
} 
g) Propuestas para hacer frente a la problemática: desde la implementación de mecanismos técnicos y de gobernanza ambiental o economía verde a la creación de tribunales internacionales de justicia ambiental y el reconocimiento de la deuda ecológica de los países del Norte.

A continuación, se desarrollarán los aspectos más destacados de los posicionamientos de cada uno de esos países en las últimas Conferencias de las Partes (en adelante COP) desde la COP 15 de Conpenhague hasta el Acuerdo de París de 2015, que luego se sintetizarán en una tabla comparativa.

Ecuador. En los últimos años Ecuador ha sido caracterizado como un inesperado pionero del desarrollo bajo en carbono (Edwards \& Timmons, 2015). Una serie de propuestas novedosas efectuadas por el país en los foros internacionales sostienen tal afirmación: el Proyecto Yasuní-ITT ${ }^{8}$, la creación de una Corte Internacional de Justicia Ambiental y la Declaración Universal de los Derechos de la Naturaleza junto a Bolivia y a la Conferencia Mundial de los Pueblos sobre el Cambio Climático y los Derechos de la Madre Tierra (Correa, 2015; Ministerio de Comunicación de Bolivia, 2015).

Pero lo que subyace al planteo de Ecuador es la crítica radical al capitalismo financiarizado: que la lucha contra el cambio climático sea la condición de posibilidad para la emergencia de una nueva estructura financiera internacional (Falconí, 2009; Correa, 2015) basada en acuerdos internacionales vinculantes que permitan hacer efectivas las responsabilidades de los países más industrializados en el calentamiento global mediante la asunción de sus deudas ecológicas para con el Sur: "El reconocimiento de la Deuda Ecológica por responsabilidades históricas de los países ricos, permitiría operativizar el concepto de las responsabilidades comunes pero diferenciadas" (Falconí, 2009).

En esta línea, Ecuador se ha posicionado en contra de que el financiamiento y las tecnologías para la mitigación sirvan a la profundización de la dependencia de los Países del Sur. Por un lado, ha planteado que tales tecnologías debieran ser declaradas internacionalmente "como bienes públicos globales, garantizando su libre acceso" (Correa, 2015). Por otro, el desarrollo de "programas innovadores sobre alivio de la deuda externa" (Sánchez \& Zambrano, 2010) y que el Fondo Verde para el Clima no se constituya en un nuevo medio para el crecimiento de las deudas externas soberanas.

En cuanto a la relación entre mitigación y adaptación, Rafael Correa ha formulado una idea por la cual se busca limitar cualquier exigencia a los países menos desarrollados para la adopción forzosa de políticas, instrumentos y tecnologías: "No será posible conservar nada en los países más pobres, si esto no tiene como resultado una mejora clara y concreta en el nivel de vida de las poblaciones" (Presidencia República del Ecuador, 2015). En este sentido, Fander Falconí ha afirmado que los países no-industrializados son "como fumadores pasivos" y que, por lo tanto, "La reducción de emisiones deben realizarla los países que están por encima del promedio mundial tolerable, que son los que han producido histórica y actualmente la mayor parte de dióxido de carbono" (Falconí, 2009).

Junto a Bolivia, Ecuador ha llevado al mundo el concepto del Sumak Kawsay (Buen Vivir) de los pueblos originarios andinos $\mathrm{y}$ ha sostenido este posicionamiento formando parte de diferentes coaliciones como el G 77 + China y el LMDC en las negociaciones de cambio climático. Asimismo, formando parte activa del ALBA ha llevado sus propuestas al seno de la Unión de Naciones Suramericanas (UNASUR) y de la Comunidad de Estados Latinoamericanos y Caribeños (CELAC).

Argentina. También nuestro país sostuvo posiciones críticas, aunque más moderadas que la de Ecuador, respecto de la desigualdad del sistema internacional y la reticencia de los países del Norte a asumir sus responsabilidades. Cabe recordar las afirmaciones del por entonces Canciller Taiana en la COP 15 de Copenhague: "los países desarrollados pretenden transferir su inmensa deuda ambiental y

\footnotetext{
${ }^{8}$ Que proponía evitar la explotación petrolera en unos de los sitios de mayor diversidad del Globo, el Parque Nacional Yasuní, a cambio de un aporte de U\$\$ 3.600 millones de la comunidad internacional. La propuesta finalmente fracasó en 2013 al recibir solamente USS 129 millones de aportes y Rafael Correa anunció la explotación de petróleo afirmando que "El mundo nos ha fallado (...) el factor fundamental en el fracaso es que el mundo es una gran hipocresía y la lógica que prevalece no es la de la justicia, sino la del poder" (Mena Erazo, 2013).
} 
las obligaciones que ésta conlleva a los países en desarrollo. Ésta es la razón principal que impide alcanzar un consenso" (Discurso de Taiana, 17 de diciembre de 2009). En la misma línea, en el marco de la COP 20 de Lima, el por entonces Vicepresidente Amado Boudou afirmaba que "El abordaje del cambio climático no puede desvincularse de la agenda del desarrollo, la erradicación de la pobreza y mejora de la distribución del ingreso entre países" (Discurso del Vicepresidente Amado Boudou, 10 de diciembre de 2014).

En ese sentido, para Argentina la interpretación del PRCPD debía efectuarse en base al principio de responsabilidades históricas y el derecho al desarrollo de los países del Sur: "La vigencia del principio de responsabilidades históricas, contenido en el párrafo preambular 3, será firmemente sostenida por la República Argentina como una de las formas de asegurar que los países en desarrollo puedan continuar sus procesos de desarrollo, en especial, en lo que se refiere a erradicación de la pobreza y promoción de la inclusión social” (Visión de la República Argentina, abril de 2012).

Asimismo, Argentina se pronunció en favor de la adopción de un mecanismo de pérdidas y daños para hacer efectiva la responsabilidad de los países del Norte, la transferencia masiva de tecnologías hacia el sur que, por un lado, eviten la destrucción de empleos y, por otro, no se basen en la adquisición de patentes o productos tecnológicos terminados sino en la participación en esos desarrollos.

Para sostener estas posiciones, Argentina formó parte del G77 + China pero, principalmente, se articuló a los posicionamientos de países del ALBA en la Coalición LMDC. No obstante, durante la COP 21 de París en diciembre de 2015 se produjo el cambio de signo político en el Gobierno con la asunción de Mauricio Macri por la Alianza Cambiemos. Lo que significó un importante giro en el posicionamiento de nuestro país, encabezado por el enviado presidencial Juan Carlos Villalonga ${ }^{9}$, orientado a "bajar los decibeles" de los planteos que el país venía adoptando en las negociaciones previas. Específicamente, en la apertura a la articulación con "un más amplio espectro de países" para aprovechar las "oportunidades" de formar parte de otras coaliciones que promuevan acuerdos climáticos "pragmáticos" (Nodal, 14 de diciembre de 2015; Clarín, 8 de diciembre de 2015).

Chile. Si bien ha afirmado el PRCPD, Chile ha asumido desde hace varios años una postura que prioriza el consenso y el acuerdo entre las partes: "Hacemos un llamado planteando un caso proactivo de desarrollo y de protección del clima (...) un relato constructivo que ponga de relieve la cooperación, desafiando las lógicas imperantes de Norte contra Sur, o de grande contra pequeño, las que solo antagonizan e impiden la generación de consensos" (Ministra María Ignacia Benítez, Segmento de Alto Nivel COP 18, citado en: Clavería, 2016).

De tal modo, la postura de Chile pone el acento, dada la vulnerabilidad de los países latinoamericanos al cambio climático, en la necesidad de adoptar medidas urgentes para el logro de un "acuerdo jurídicamente vinculante pare la reducción de emisiones", en el establecimiento del Fondo Verde para el Clima y la adopción de "compromisos más ambiciosos" por parte de todos los países (Intervención de Chile Plenario, Segmento Alto Nivel, COP 17). Este último punto es nodal para entender la diferencia en el posicionamiento chileno en su promoción de una interpretación flexible del PRCPD basado en que, como ha señalado Ricardo Lagos ${ }^{10}$, "las emisiones acumuladas de los países de ingreso medio en América Latina y el mundo representan un porcentaje significativo de las emisiones globales y nuestras contribuciones al cambio climático global no pueden ser ignoradas" (Lagos, 2015: x). Por lo tanto, Chile junto a AILAC es promotor de una postura pragmática que fortalezca "la acción climática por parte de todos los países antes que perpetuar una competencia hasta el fondo" (Lagos, 2015: xii), zanjando de esa manera las tensiones y antagonismos Norte-Sur.

\footnotetext{
${ }^{9}$ Villalonga, actual Diputado Nacional por Cambiemos, se auto denomina "diputado verde" y es un destacado militante de la causa ambiental que ha formado parte de organizaciones no gubernamentales como Greenpeace y Los Verdes.

${ }^{10}$ Ex presidente chileno entre los años 2000 a 2006 y enviado especial de Naciones Unidas para el cambio climático entre 2008 y 2010).
} 
La propuesta principal, en tal sentido, pasa por establecer, por un lado, mecanismos de transparencia en tanto "fundamento central de toda acción climática" y, por otro, de mostrar al mundo compromisos y presentaciones de informes y comunicaciones nacionales (Discurso de Michelle Bachelet en COP 22). Es decir, de constituirse en un caso ejemplar de la gobernanza contra el cambio climático hacia adentro de sus fronteras y, al mismo tiempo, de constituirse en un actor proactivo o "broker" del consenso ambiental internacional.

Además de AILAC, Chile promovió la creación de la denominada "Iniciativa Chile-Brasil" para el apoyo de la COP 20 de Lima y en aras del Acuerdo finalmente alcanzado en París en $2015^{11}$. Tal iniciativa fue determinante, junto al "Diálogo de Cartagena" y la "Alianza de Amigos del Futuro" para el fortalecimiento de la Coalición de Gran Ambición que finalmente en 2015 logrará el Acuerdo de París quebrando la oposición del LMDC (Hirsch, 2016).

Brasil. Para algunos autores Brasil es un país que ha adoptado, a lo largo de los quince años de negociaciones climáticas, posiciones ambiguas o contradictorias. En ciertos momentos como país líder de las negociaciones y en otras como un "spoiler" o saboteador de acuerdos. Al tiempo que se suele destacar sus logros en materia de reducción de emisiones a partir de reducción de deforestación y sus posturas "progresistas" al promover compromisos internacionales ambiciosos, también se señala su tendencia a "bloquear el progreso en defensa de su soberanía nacional bajo la bandera de los principios básicos de la CMNUCC" (Edwards \& Timmons, 2015: 69).

Pero en este trabajo buscamos no reducir los posicionamientos al par progresistas/saboteadores ni a asumir el supuesto de tal oposición: que la efectividad de la lucha contra el cambio climático depende más de la adopción de instrumentos de gobernanza climática que de la transformación del sistema político-económico internacional. Por lo tanto, nos interesa dar cuenta de la posición brasilera en base a los ejes de problematización antes propuestos.

Brasil ha sido un país pionero en la defensa del posicionamiento de los países menos desarrollados como promotor del principio de responsabilidades históricas de los países más industrializados, ya sea integrando el G77 + China o la Coalición BASIC. Como señalaba Luiz Inazio Lula da Silva en la COP 15 , el hecho de que ciertos países emergentes hayan experimentado en los años 2000 un crecimiento y desarrollo importante no se debe perder de vista que los países del BASIC siguen teniendo altos niveles de pobreza, por lo cual se debe "mantener el desarrollo de los países en desarrollo" porque "Pasamos un siglo sin crecer, mientras que otros crecían mucho. Ahora que empezamos a crecer, no es justo que volvamos a hacer el sacrificio" (Discurso do presidente Luiz Inácio Lula da Silva, COP-15).

Como así también, que la causa climática y la transparencia demandada por los países del Norte para el financiamiento no deben ser utilizadas para la "intrusión" de éstos en los países más pobres ya que "La experiencia que tenemos, ya sea del Fondo Monetario Internacional o del Banco Mundial en nuestros países, no es recomendable que continúe en el siglo XXI" (Discurso do presidente Luiz Inácio Lula da Silva, COP-15).

No obstante, la articulación de Brasil a la mencionada Iniciativa Chile-Brasil junto a la Alianza de Amigos del Futuro y la Coalición de Gran Ambición lo ha acercado en los últimos años a las posturas de AILAC en alianza con países como Chile y México. En una postura mucho más conciliadora que su antecesor, Dilma Roussef señalaba en la COP 21 que el PRCPD es piedra angular del Acuerdo y que: "Corresponde al acuerdo de París propiciar las condiciones para que todos los países en desarrollo puedan recorrer los caminos de la economía de bajo carbono superando la extrema pobreza y reduciendo las desigualdades".

\footnotetext{
${ }^{11}$ Esta iniciativa cuenta con el apoyo de la CEPAL, el PNUMA y el financiamiento de la Comisión Europea a través del programa EUROCLIMA y de la cooperación francesa (EUROCLIMA, 24 septiembre 2014).
} 
Tabla comparativa: posicionamientos de Ecuador, Argentina, Chile y Brasil en recientes negociaciones internacionales sobre cambio climático

\begin{tabular}{|c|c|c|c|c|}
\hline Países & \multirow[b]{2}{*}{ Ecuador } & \multirow[b]{2}{*}{ Argentina } & \multirow[b]{2}{*}{ Chile } & \multirow[b]{2}{*}{ Brasil } \\
\hline $\begin{array}{l}\text { Ejes de } \\
\text { problematización }\end{array}$ & & & & \\
\hline $\begin{array}{l}\text { 1) Coaliciones y grupos } \\
\text { más relevantes que } \\
\text { integran }\end{array}$ & G77 + China, LMDG & $\begin{array}{l}\text { G77+China, LMDG } \\
\text { (desde el cambio de } \\
\text { Gobierno en } 2015 \\
\text { abandona el } \\
\text { LMDG) }\end{array}$ & $\begin{array}{l}\text { G77+China, AILAC, } \\
\text { Iniciativa Chile-Brasil, } \\
\text { Coalición de Gran } \\
\text { Ambición }\end{array}$ & $\begin{array}{l}\text { G77+China, BASIC, } \\
\text { Iniciativa Chile-Brasil, } \\
\text { Coalición de Gran } \\
\text { Ambición }\end{array}$ \\
\hline $\begin{array}{l}\text { 2) Organismos de } \\
\text { integración regional o } \\
\text { extra regional que } \\
\text { integran }\end{array}$ & $\begin{array}{l}\text { ALBA, UNASUR, } \\
\text { CELAC }\end{array}$ & $\begin{array}{l}\text { UNASUR, } \\
\text { CELAC, } \\
\text { MERCOSUR }\end{array}$ & $\begin{array}{l}\text { Alianza del Pacífico, } \\
\text { UNASUR, CELAC }\end{array}$ & $\begin{array}{l}\text { BRICS, UNASUR, } \\
\text { CELAC, MERCOSUR }\end{array}$ \\
\hline $\begin{array}{l}\text { 3) Naturaleza del } \\
\text { problema del cambio } \\
\text { climático }\end{array}$ & $\begin{array}{l}\text { Problema político } \\
\text { antes que técnico } \\
\text { basado en desigualdad } \\
\text { de sistema } \\
\text { internacional y } \\
\text { provocado por } \\
\text { emisiones históricas } \\
\text { de países del Norte }\end{array}$ & $\begin{array}{l}\text { Problema que no } \\
\text { debe verse aislado } \\
\text { de temas como } \\
\text { seguridad } \\
\text { alimentaria, } \\
\text { desarrollo, pobreza } \\
\text { y desigualdad entre } \\
\text { países. Causado por } \\
\text { emisiones históricas } \\
\text { de países } \\
\text { desarrollados }\end{array}$ & $\begin{array}{l}\text { Énfasis en } \\
\text { vulnerabilidad al } \\
\text { cambio climático por } \\
\text { parte de países } \\
\text { Latinoamericanos. } \\
\text { Urgencia en adoptar } \\
\text { medidas para no } \\
\text { sobrepasar los } 2 \text { grados } \\
\text { centígrados }\end{array}$ & $\begin{array}{l}\text { Causado por países del } \\
\text { Norte. Primero debe } \\
\text { asegurarse el derecho al } \\
\text { desarrollo de todos los } \\
\text { países. }\end{array}$ \\
\hline $\begin{array}{l}\text { 4) Interpretación al } \\
\text { Principio de } \\
\text { Responsabilidades } \\
\text { Comunes pero } \\
\text { Diferenciadas (PRCPD) }\end{array}$ & $\begin{array}{l}\text { Interpretación fuerte } \\
\text { en base a } \\
\text { responsabilidades } \\
\text { históricas y principio } \\
\text { de equidad. Deuda } \\
\text { ecológica de Países } \\
\text { del Norte }\end{array}$ & $\begin{array}{l}\text { Interpretación } \\
\text { fuerte en base a } \\
\text { responsabilidades } \\
\text { históricas de países } \\
\text { del Norte }\end{array}$ & $\begin{array}{l}\text { Interpretación flexible: } \\
\text { la acción climática debe } \\
\text { ser efectuada por todos } \\
\text { los países evitando } \\
\text { perpetuar el } \\
\text { antagonismo Norte-Sur }\end{array}$ & $\begin{array}{l}\text { De interpretación fuerte a } \\
\text { interpretación flexible: } \\
\text { acuerdo que permita } \\
\text { desarrollo de todos los } \\
\text { países basado en } \\
\text { economías bajas en } \\
\text { carbono }\end{array}$ \\
\hline $\begin{array}{l}\text { 5) Financiamiento para } \\
\text { enfrentar al cambio } \\
\text { climático }\end{array}$ & $\begin{array}{l}\text { Deuda ecológica de } \\
\text { países del Norte para } \\
\text { con los del Sur. } \\
\text { Cambio climático no } \\
\text { debe servir para } \\
\text { endeudamiento de } \\
\text { países pobres }\end{array}$ & $\begin{array}{l}\text { Contra } \\
\text { imposiciones de } \\
\text { países del Norte } \\
\text { que permitan } \\
\text { trasladar sus } \\
\text { responsabilidades a } \\
\text { países del Sur }\end{array}$ & $\begin{array}{l}\text { Apoya creación de } \\
\text { Fondo Verde para el } \\
\text { Clima. Énfasis en } \\
\text { transparencia en } \\
\text { financiamiento } \\
\text { climático }\end{array}$ & $\begin{array}{l}\text { En favor del } \\
\text { financiamiento, pero } \\
\text { contra intromisión de } \\
\text { organismos multilaterales } \\
\text { de crédito }\end{array}$ \\
\hline $\begin{array}{l}\text { 6) Tecnologías para } \\
\text { enfrentar el cambio } \\
\text { climático }\end{array}$ & \begin{tabular}{|l|} 
Tecnologías de \\
mitigación deben ser \\
de acceso libre. Contra \\
privatización del \\
conocimiento
\end{tabular} & $\begin{array}{l}\text { Transferencia } \\
\text { masiva de } \\
\text { tecnologías a países } \\
\text { en desarrollo }\end{array}$ & $\begin{array}{l}\text { Transferencia de } \\
\text { tecnologías ambiciosa a } \\
\text { través de financiamiento } \\
\text { de organismos } \\
\text { multilaterales de crédito }\end{array}$ & $\begin{array}{l}\text { Transferencia de } \\
\text { tecnologías en base al } \\
\text { respeto de soberanías } \\
\text { nacionales }\end{array}$ \\
\hline $\begin{array}{l}\text { 7) Adaptación y } \\
\text { mitigación al cambio } \\
\text { climático }\end{array}$ & \begin{tabular}{|l|} 
La reducción de \\
emisiones deben \\
realizarla los países \\
que están por encima \\
del promedio mundial \\
tolerable. Carácter \\
voluntario de acciones \\
de mitigación para el \\
Sur. Énfasis en
\end{tabular} & $\begin{array}{l}\text { Carácter voluntario } \\
\text { de acciones de } \\
\text { mitigación de } \\
\text { países en desarrollo } \\
\text { dependientes del } \\
\text { financiamiento } \\
\text { provisto por países } \\
\text { desarrollados. } \\
\text { Promueve incluir y }\end{array}$ & $\begin{array}{l}\text { Énfasis en mitigación } \\
\text { con acciones concretas } \\
\text { dentro de sus fronteras }\end{array}$ & $\begin{array}{l}\text { En favor de carácter } \\
\text { voluntario de acciones de } \\
\text { mitigación para países en } \\
\text { desarrollo y poderes } \\
\text { emergentes }\end{array}$ \\
\hline
\end{tabular}




\begin{tabular}{|c|c|c|c|c|}
\hline & adaptación & $\begin{array}{l}\text { dar prioridad a } \\
\text { adaptación }\end{array}$ & & \\
\hline $\begin{array}{l}\text { 8) Propuestas o vías de } \\
\text { acción para hacer frente } \\
\text { a problemática }\end{array}$ & $\begin{array}{l}\text { Nueva estructura } \\
\text { financiera } \\
\text { internacional. } \\
\text { Declaración Universal } \\
\text { de los Derechos de la } \\
\text { Naturaleza. } \\
\text { Tecnologías de } \\
\text { mitigación declaradas } \\
\text { bienes públicos } \\
\text { universales de libre } \\
\text { acceso. Mecanismos } \\
\text { para hacer efectivas } \\
\text { las pérdidas y daños y } \\
\text { la responsabilidad de } \\
\text { emisores históricos de } \\
\text { carbono. Corte } \\
\text { Internacional de } \\
\text { Justicia Ambiental. }\end{array}$ & $\begin{array}{l}\text { Adecuación a } \\
\text { tecnologías no por } \\
\text { adquisición de } \\
\text { patente sino por } \\
\text { participación en su } \\
\text { desarrollo. } \\
\text { Afirmación del } \\
\text { Protocolo de Kyoto. } \\
\text { Cambio en sistema } \\
\text { productivo no debe } \\
\text { afectar puestos de } \\
\text { trabajo. }\end{array}$ & $\begin{array}{l}\text { Compromiso con la } \\
\text { adopción de un nuevo } \\
\text { régimen climático. } \\
\text { Promueve posturas } \\
\text { pragmáticas a nivel } \\
\text { regional orientadas al } \\
\text { logro de consensos } \\
\text { internacionales. } \\
\text { Acciones de adaptación } \\
\text { y mitigación nacionales. } \\
\text { Para países } \\
\text { latinoamericanos: rol de } \\
\text { "brokers" que permitan } \\
\text { superar tensiones Norte- } \\
\text { Sur }\end{array}$ & $\begin{array}{l}\text { Proponente originario de } \\
\text { principio de } \\
\text { responsabilidades } \\
\text { históricas de grandes } \\
\text { emisores globales. } \\
\text { Modelo brasilero de } \\
\text { reducción de emisiones a } \\
\text { partir de freno a } \\
\text { deforestación. De } \\
\text { afirmación de protocolo } \\
\text { de Kioto a postura } \\
\text { pragmática en Coalición } \\
\text { de Gran Ambición. }\end{array}$ \\
\hline
\end{tabular}

\section{Consideraciones finales}

Este trabajo ha permitido dar cuenta de las diferencias en los posicionamientos de los populismos frente a las derechas o experiencias no populistas en América Latina. Mientras los primeros suelen tener posturas más radicalizadas y críticas para con el sistema económico-político internacional, los segundos tienden a asumir el rol de mediadores o brokers para el logro de consensos políticos internacionales.

Los populistas se orientan mayormente a la defensa de sus soberanías nacionales y del derecho al desarrollo de sus países, como así también de la necesaria adopción de mecanismos vinculantes para que los países del Norte se vean obligados a asumir su deuda ecológica generada a partir de sus emisiones históricas de carbono. Asimismo, propugnan la creación de innovadoras formas de financiamiento y transferencia de tecnología que eviten la revictimización de los países menos desarrollados en la lucha contra el cambio climático.

Por lo tanto, a partir de este análisis, los populismos no se presentan como puras amenazas para la causa ambiental o meras expresiones de una diplomacia irracional, sino como experiencias que han dado vida al debate internacional de los últimos años, visibilizando el antagonismo Norte-Sur presente desde los orígenes de la historia ambiental contemporánea ${ }^{12}$. Cabe destacar que tal visibilización no aparece como antojadiza sino como una causa legítima que, en función de una significación diversa de los problemas ambientales, es capaz de ofrecer al mundo propuestas innovadoras para hacer frente al calentamiento global, la desigualdad y la pobreza.

Por lo tanto, desde nuestra perspectiva, no se trata de identificar los obstáculos al logro de acuerdos o a la eficacia del régimen internacional de cambio climático, sino a la comprensión crítica de estas discusiones y las diferentes lógicas políticas en pugna.

\footnotetext{
${ }^{12} \mathrm{Al}$ respecto ver: Foa Torres, 2017a, 2017b.
} 
Cabe advertir, por último, que el campo de los debates ambientales es un terreno propicio para concepciones que intentan negar el carácter constitutivo del antagonismo social y reducirlo a un mero conflicto de índole técnica. Por lo tanto, es necesario profundizar los estudios desde perspectivas latinoamericanas y críticas que eviten suponer a los populismos como regímenes políticos esencialmente contrarios a acuerdos internacionales o, incluso, antiambientalistas; para avanzar hacia los fundamentos que sostienen tales posturas, usualmente sostenidos en la complejidad política de las vinculaciones entre política ambiental, comercio internacional, desigualdad entre países y desigualdad hacia adentro de los países del Sur.

\section{Bibliografía}

Bodansky, D. \& Rajamani, L. (2016). Evolution and Governance Architecture of the Climate Change Regime. In Sprinz, D. and Luterbacher, U. (eds). International Relations and Global Climate Change. London: MIT Press.

Bueno, P. (2017). El Acuerdo de París: ¿una nueva idea sobre la arquitectura climática internacional? Relaciones Internacionales, 33, 75-95.

Clavería, L. (2016). De Copenhague a París: análisis de los discursos de Brasil, Chile y Ecuador en las conferencias de las partes (2009 - 2015). Direitos Emergentes na Sociedade Global, 5(2), 94-115.

De La Torre, C. (2014). The People, Democracy, and Authoritarianism in Rafael Correa's Ecuador. Constellations, 21 (4), 457-466.

Edwards, G. \& Timmons R. J. (2015). A fragmented continent. Latin America and the Global Politics of Climate Change. Cambridge: The MIT Press.

Foa Torres, J. (2017a). Neoliberalismo, deuda y ambiente. En: Piñero, M.T y Bonetto, M. S. (comps.) Tensiones en la democracia argentina: Rupturas y continuidades en torno al neoliberalismo. Córdoba: CEA-FCS-UNC.

Foa Torres, J. (2017b). Lógica del riesgo y patrón de desarrollo sustentable en América Latina Políticas de gestión ambientalmente adecuada de residuos peligrosos en la ciudad de Córdoba. Córdoba: Editorial del Centro de Estudios Avanzados.

Glynos, J. \& Howarth, D. (2007). Logics of Critical Explanation in Social and Political Theory. U.K.: Routledge.

Hirsch, T. (2016). El papel de las alianzas en la política internacional de lucha contra el cambio climático tras París. Berlín: Friedrich-Ebert-Stiftung.

Laclau, E. (2006). La deriva populista y la centroizquierda latinoamericana. Nueva Sociedad, 205, 5661.

(2008). La razón populista. Buenos Aires: Fondo de Cultura Económica.

Laclau, E. \& Mouffe, C. (2004). Hegemonía y estrategia socialista. Hacia una radicalización de la democracia. Buenos Aires: Fondo de Cultura Económica.

Mudde, C. \& Rovira Kaltwasser, C. (2012). Populism in Europe and the Americas: Threat or Corrective for Democracy? Cambridge: Cambridge University.

Meijers, E. (2011). Populism in Europe. Vienna: Green European Foundation. 
Panizza, F. (2005). Unarmed Utopia Revisited: The Resurgence of Left-of-Centre Politics in Latin America. Political Studies, 53, 716-734.

Rovira Kaltwasser, C. (2014a). Latin American Populism: Some Conceptual and Normative Lessons. Constellations, 21(4), 494-504.

(2014b). La derecha en América Latina y su lucha contra la adversidad.

Nueva Sociedad, 254, 34-45.

Sorsa, P. (1995). El medio ambiente en el contexto del comercio internacional. En SELA/UNCTAD: Comercio y medio ambiente, 101-109. Caracas: Nueva Sociedad.

Stavrakakis, Y. (2015). Populism in power: Syriza's challenge to Europe. Juncture, 21(4), 273-280.

Svampa, M. (2016). "América Latina: Fin de ciclo y populismos de alta intensidad". En A.A.V.V.: Rescatar la esperanza. Más allá del neoliberalismo y el progresismo, 63-90. Barcelona: Entre Pueblos.

\section{Fuentes Documentales}

Clarín (2015). Giro en la posición argentina sobre el calentamiento global, 9 de diciembre de 2015.

Discurso del Presidente Rafael Correa ante COP 21 (2015), 30 Noviembre de 2015, París.

Discurso del Ministro Jorge Taiana en la COP 15 (2009), 17 diciembre de 2009.

Discurso do presidente Luiz Inácio Lula da Silva (2009), COP 15, 18 de diciembre de 2009, sessão plenária de debate informal $15^{\mathrm{a}}$ Conferência das Partes da Convenção das Nações Unidas sobre Mudança do Clima.

Discurso de Michelle Bachelet en COP 22 Marruecos (2016), 15 de noviembre de 2016.

Discurso del Vicepresidente Amado Boudou en COP 20 de Lima (2014), 10 de diciembre de 2014.

EUROCLIMA (2014). Reunión de Jefes Negociadores de Cambio Climático, 24 septiembre 2014. Recuperado de: http://www.euroclima.org

FALCONÍ, F. (2009), Discurso del Ministro de Relaciones Exteriores Fander Falconí, COP15, Copenhague.

Intervención de Chile Plenario, Segmento Alto Nivel, COP 17.

Lagos, R. (2015), "Foreword", in: Edwards \& Timmons Roberts: A fragmented continent. Latin America and the Global Politics of Climate Change, Cambridge: The MIT Press.

Mena erazo, P. (2013), “Por qué fracasó el proyecto ambiental de Yasuní en Ecuador?”, BBC Mundo, 16 agosto 2013.

Ministerio de Comunicación de Bolivia (2015), Preferimos estar sometidos al pueblo y no a los imperios, Discurso del Presidente Evo Morales Ayma, Conclusiones de la CMPCC-Tiquipaya, $n^{\circ}$ 701, martes 13 de octubre de 2015.

Nodal (2015). Juan Carlos Villalonga, jefe de la delegación argentina en la COP21: "El gran logro de la Cumbre fue político: ganó el pragmatismo", 14 de diciembre de 2015.

NU (1992). Convención Marco de las Naciones Unidas sobre el Cambio Climático, Río de Janeiro. 
Presidencia República del Ecuador (2015). Ponencia del Presidente Ecuatoriano Rafael Correa Delgado en el taller sobre la dimensión moral del cambio climático. Estado Vaticano, 28 de abril de 2015.

Sanchez M. \& ZAmbrano, M. (2010). Retos para el Ecuador y la Comunidad Internacional frente al cambio climático. AFESE $n^{\circ} 54,155-174$.

Visión de la República Argentina (2012). Grupo de Trabajo Ad-Hoc para la Plataforma de Durban para Acción Mejorada, abril de 2012. 